\title{
Reversible Thermal Transition of Soluble Branched Chains from Slightly Acid-treated Potato Starch
}

\author{
Koji Takahashi, ${ }^{\dagger}$ Hiroshi Kondo, Hiroshi Kuroiwa, Yoshiko Yokote, ${ }^{\S}$ \\ and Makoto HATTORI \\ Department of Applied Biological Science, Faculty of Agriculture, Tokyo University \\ of Agriculture and Technology, Tokyo 183-8509, Japan \\ ${ }^{\S}$ Department of Chemistry, Faculty of Science, Josai University, Saitama 350-0248, Japan
}

Received December 13, 1999; Accepted March 9, 2000

The reversible thermal transition of soluble branched starch chains prepared from slightly acid-treated potato starch granules (ATS) was investigated. Potato starch was immersed in $15 \%$ sulfuric acid to obtain ATS with a $1 \%$ hydrolysis rate. About half of the molecules of ATS, which spontaneously formed large aggregates with a mass of a few million daltons in aqueous solution, was fractionated and soluble branched starch chains with a relative molecular weight $\left(M_{\mathrm{r}}\right)$ of $8.91 \times$ $10^{4}$ were obtained. Structural analysis indicated that the soluble branched starch chains consisted of three unit chains with $M_{\mathrm{r}} 7,900$ and 21 unit chains with $M_{\mathrm{r}} 2,700$. DSC and FT-IR measurements showed that the soluble branched starch chains underwent a reversible thermal transition, which is considered to be a helix-coil transition, during heating and cooling, but a debranched sample and $\beta$-limit dextrins showed substantially different thermal behavior, indicating the contribution of the ordered structure of the branched chains.

Key words: acid-treated starch; thermal transition; DSC; FT-IR

Starch granules are generally composed of amylopectin and amylose. Amylopectin is the major component of most starches and branched chains of amylopectin molecules associate through intra- and inter-chain interactions to form the crystalline structure of starch granules. This is considered to be important to the physical properties of starch. Starch granules readily gelatinize in water upon heating and retrograde upon cooling, resulting in the dissociation of starch chains in crystalline regions in the granule upon heating and their partial reassociation during cooling. Considerable progress has been made in the characterization of the fine structure of starches, and the relationships among the length of the branched chain of amylopectin, the amylose content, and the gelatinization of starches have been studied., ${ }^{1,2)}$
Granular starch has been frequently examined in studies aiming to elucidate and regulate its gelatinization and retrogradation behavior, using various analytical methods such as X-ray diffractometry, ${ }^{3,4)}$ thermal analysis, ${ }^{5,6)}$ electronmicroscopy, ${ }^{7)}$ FT-IR, ${ }^{8-10)}$ Raman spectroscopy, ${ }^{11)}$ and $\mathrm{NMR}^{12,13)}$ with attention paid to practical application. However, since starch granules are insoluble and since starch molecules are not uniform in terms of molecular structure, molecular weight, and molecular organization or packing, it is difficult to understand the integrated behavior of different molecules in the starch granules on the basis of the thermal transition of individual starch molecules. This underlines the importance of obtaining a sample of soluble starch with branched chains showing a uniform chemical structure corresponding to amylopectin molecules with the thermal transition features described above.

In aqueous solution, acids preferentially hydrolyze the amorphous region of amylopectin in starch granules, ${ }^{14)}$ resulting in an increase in water-solubility. We have previously reported that about half of the slightly acid-treated starch (ATS) in solution spontaneously associated to form large aggregates with a mass of a few million daltons in water or $0.01 \mathrm{M}$ borate buffer ( $\mathrm{pH} 7.0$ ), whereas the aggregation depended on the presence of potassium chloride, and that these soluble starch chains had a branched structure and underwent thermal transition in a process like gelatinization. ${ }^{15)}$ These findings suggested that the soluble branched starch chain in ATS could be prepared for use as a model for investigating the thermal properties of starch molecules based on the conformational changes observed. However, the soluble branched starch chains prepared previously had a wide distribution of molecular weights and the chemical structure remains unknown.

The objective of this study was to obtain soluble and more homogeneous starch chains with a definite

\footnotetext{
† To whom correspondence should be addressed. Fax: +81-42-367-5711; E-mail: k-taka@cc.tuat.ac.jp

Abbreviations: DSC, differential scanning calorimetry; FT-IR, Fourier transform infrared spectroscopy
} 
branched structure and to elucidate the peculiar thermal transition of the soluble branched starch chains by thermal analysis and Fourier transform infrared spectroscopy.

\section{Materials and Methods}

Starch and related saccharides. Potato starch (large granule preparation; Hokuren Research Institute, Sapporo, Japan) was used after being washed repeatedly with distilled water at $4^{\circ} \mathrm{C}$ and air-dried (moisture, 17\%, dry basis). Pullulan (P-800, P-400, P-200, P-100, P-50, P-20, P-10, and P-5) was purchased from Shoko Co., Ltd. (Tokyo, Japan). Dextran (T-2000, T-500, T-70, T-40, and T-10) was purchased from Amersham Pharmacia Biotech (Uppsala, Sweden). Maltotetraose $\left(\mathrm{G}_{4}\right)$, maltopentaose $\left(\mathrm{G}_{5}\right)$, maltohexaose $\left(\mathrm{G}_{6}\right)$, maltoheptaose $\left(\mathrm{G}_{7}\right)$, and maltooctaose $\left(\mathrm{G}_{8}\right)$ were obtained from Nihon Shokuhin Kako Co., Ltd. (Tokyo, Japan). Glucose $\left(\mathrm{G}_{1}\right)$, maltose $\left(\mathrm{G}_{2}\right)$, maltotriose $\left(\mathrm{G}_{3}\right)$, and amylose (from potato, $M \mathrm{r} 158,000)$ were purchased from Wako Pure Chemical Ind. (Osaka, Japan).

Enzymes. Sweet potato $\beta$-amylase (EC 3.2.1.2; Sigma, Type 1-B) was purified by affinity chromatography using a cyclodextrin-Sepharose 6B column. ${ }^{16}$ Pseudomonas isoamylase (EC 3.2.1.68) was purchased from Seikagaku Kogyo Co. (Tokyo, Japan). Pullulanase (EC 3.2.1.41) was kindly provided by Dr. Sakano (Tokyo University of Agriculture and Technology, Tokyo, Japan).

Acid-treated starch (ATS). Potato starch (40 g) was immersed in 1.61 of $15 \%(\mathrm{w} / \mathrm{w})$ sulfuric acid at $25^{\circ} \mathrm{C}$ to obtain a $1 \%$ hydrolysis rate, as described by Kainuma and French. ${ }^{14)}$ The degree of hydrolysis was calculated from the following, $(0.9 \times$ dissolved saccharides $) \times 100 /($ starch weight $)$, where the concentration of dissolved saccharides was measured by the phenol-sulfuric acid method. ${ }^{17)}$ The sulfuric acid was thoroughly removed by collecting the ATS on a G-4 glass filter and washing with distilled water, and the ATS was air-dried. For DSC, the ATS was used without air-drying.

Fractionation of ATS. ATS (400 mg) was dissolved in $20 \mathrm{ml}$ of distilled water by heating at $80^{\circ} \mathrm{C}$ for 20 min. The ATS solution was put on a Toyopearl HW65S column (Tosoh, Japan; column size, $2.6 \mathrm{~cm}$ i.d. $\times 100 \mathrm{~cm}$ ) and elution was done with distilled water as the mobile phase at a flow rate of $60 \mathrm{ml} / \mathrm{hr}$ at $4^{\circ} \mathrm{C}$. The peak-1 component (P-1) eluted at the void volume was collected and recovered by lyophilization. P-1 was dissolved in $0.01 \mathrm{M}$ borate buffer $(\mathrm{pH}$ 7.0) containing $0.1 \mathrm{M}$ potassium chloride, and put on again the chromatography column with the same buffer as the mobile phase at a flow rate of $60 \mathrm{ml} / \mathrm{hr}$.
Starch chains of P-1 were fractionated into four fractions (Frs. 1-4) according to relative molecular weights of above $50 \times 10^{4}, 20-50 \times 10^{4}, 5-20 \times 10^{4}$, and below $5 \times 10^{4}$, respectively, as estimated based on comparison with the dextran molecular weight markers T2000 $\left(\mathrm{Mr}, 2 \times 10^{6}\right)$, T500 $\left(\mathrm{Mr}, 46.1 \times 10^{4}\right)$, T70 $\left(\mathrm{Mr}, 6.56 \times 10^{4}\right)$, T40 $\left(\mathrm{Mr}, 4.01 \times 10^{4}\right)$, T10 $(\mathrm{Mr}$, $\left.1.05 \times 10^{4}\right)$, and glucose. Frs. 1-4 were dialyzed against distilled water and lyophilized.

Preparation of debranched starch chains. The lyophilized starch chains $(500 \mathrm{mg}$ ) (one of the Frs. 1-4) were dissolved in $4 \mathrm{ml}$ of $1 \mathrm{M}$ sodium hydroxide at $40^{\circ} \mathrm{C}$ with stirring for $2 \mathrm{hr}$, then diluted with $30 \mathrm{ml}$ of distilled water and adjusted to $\mathrm{pH} 6.0$ with $0.5 \mathrm{M}$ hydrochloric acid. After adding $40 \mathrm{ml}$ of $0.06 \mathrm{M}$ acetate buffer $(\mathrm{pH} 3.5)$, the sample was incubated with $26 \mathrm{IU}$ of isoamylase at $40^{\circ} \mathrm{C}$ for $24 \mathrm{hr}$. The debranched sample was dialyzed against distilled water and lyophilized. For structural analysis, the isoamylolyzate was heated at $100^{\circ} \mathrm{C}$ for $5 \mathrm{~min}$, filtered using a $0.45 \mu \mathrm{m}$ membrane filter, desalted and deproteinized by treatment with cation- and anionexchange resins (Amberlite IR-120B and IRA-410, Organo, Tokyo, Japan), and then lyophilized. The debranched sample was obtained through isoamylolysis for three times and confirmed to be completely digested with $\beta$-amylase.

Preparation of $\beta$-limit dextrins. The lyophilized P-1 or starch chains (500 mg) (one of the Frs. 1-4) was dissolved in $1 \mathrm{M}$ sodium hydroxide at $40^{\circ} \mathrm{C}$ with stirring for $2 \mathrm{hr}$, then diluted with $30 \mathrm{ml}$ of distilled water and neutralized with $0.5 \mathrm{M}$ acetic acid. After adding $40 \mathrm{ml}$ of $0.2 \mathrm{M}$ acetate buffer ( $\mathrm{pH} \mathrm{4.8)} \mathrm{con-}$ taining $1 \mathrm{~mm}$ reduced glutathione, the sample was incubated with $300 \mathrm{IU}$ of purified $\beta$-amylase at $37^{\circ} \mathrm{C}$ for $24 \mathrm{hr}$. The maltose concentration in the mixture of reaction products was measured by the Somogyi ${ }^{18)}$-Nelson ${ }^{19)}$ method. $\beta$-Limit dextrins were obtained by dialysis against distilled water and lyophilization. For structural analysis, $\beta$-amylolyzate was heated at $100^{\circ} \mathrm{C}$ for $5 \mathrm{~min}$, filtered using a 0.45 $\mu \mathrm{m}$ membrane filter, dialyzed against distilled water, and lyophilized. After the $\beta$-amylolysis was repeated three times, the $\beta$-amylolyzate was desalted and deproteinized by treatment with cation- and anionexchange resins (Amberlite IR-120B and IRA-410, Organo, Tokyo, Japan), and lyophilized. The $\beta$ amylolysis limit was measured based on the ratio of the reducing sugar content to the total sugar content as maltose, which were measured by the modified Park-Johnson method ${ }^{20)}$ and the phenol-sulfuric acid method, ${ }^{17)}$ respectively.

Preparation of the debranched $\beta$-limit dextrins. $\beta$ limit dextrins were debranched with pullulanase as follows. After isoamylolysis as described above, the 
isoamylolyzate was adjusted to $\mathrm{pH} 5.2$ with $0.1 \mathrm{M}$ sodium hydroxide and debranched with $170 \mathrm{IU}$ of pullulanase at $30^{\circ} \mathrm{C}$ for $24 \mathrm{hr}$. Thereafter, the sample of debranched $\beta$-limit dextrins was heated at $100^{\circ} \mathrm{C}$ for $5 \mathrm{~min}$, filtered using a $0.45 \mu \mathrm{m}$ membrane filter, and treated with cation- and anion-exchange resins, and lyophilized.

Size-exclusion chromatography (SEC). SEC analysis of starch chains was done using an HPLC system (Tosoh, Tokyo, Japan) with a TSKgel G5000PW $\mathrm{XL}_{\mathrm{X}}$ column $(7.8 \mathrm{ID} \times 300 \mathrm{~mm})$ for P-1, P-2, and Frs. 1-4 or a TSKgel G3000PW $\mathrm{XL}_{\mathrm{XL}}$ column $(7.8 \mathrm{ID} \times 300 \mathrm{~mm} \times$ 2) (Tosoh, Tokyo, Japan) for the debranched samples. The columns were calibrated with pullulan (P-800, Mr800,000; P-400, Mr380,000; P-200, $M r 186,000 ; \quad \mathrm{P}-100, \quad M r 100,000 ;$ P-50, Mr48,000; P-20, Mr23,700; P-10, Mr12,200; P-5, Mr5,800), maltoheptaose ( $M \mathrm{w} 1,152)$, maltotriose ( $M \mathrm{w} 504)$, maltose $(M \mathrm{w} 342)$, and glucose $(M \mathrm{w} 180)$ to estimate relative molecular weights of samples. For analysis, the lyophilized sample was dissolved in $0.01 \mathrm{M}$ borate buffer ( $\mathrm{pH} 7.0$ ) containing $0.1 \mathrm{M}$ potassium chloride by incubation at $80^{\circ} \mathrm{C}$ for $20 \mathrm{~min}$ with stirring. The sample solution was applied to the column equilibrated with the same buffer and elution was performed at a flow rate of $0.6 \mathrm{ml} / \mathrm{min}$. The refractive index was monitored.

Differential scanning calorimetry (DSC). DSC of ATS, P-1, P-2, starch chains, debranched samples, and $\beta$-limit dextrins was performed using a DSC apparatus (Seiko SSC-5020 DSC 100, Japan) as described by Takahashi et al. ${ }^{21)}$ About $15 \mathrm{mg}$ of sample and $35 \mu \mathrm{l}$ of distilled water were sealed in a $70 \mu \mathrm{l}$ Ag capsule and distilled water was used as a reference. After the first run to $120^{\circ} \mathrm{C}$ at a heating rate of $2^{\circ} \mathrm{K} / \mathrm{min}$, the heating furnace was rapidly cooled with liquid nitrogen and held at $0^{\circ} \mathrm{C}$ for $30 \mathrm{~min}$ before the second run. The lid of the capsule was opened after DSC and the sample was dissolved in distilled water by incubation at $120^{\circ} \mathrm{C}$ for $20 \mathrm{~min}$ using a sealed test tube. From the total saccharides concentration measured by the phenol-sulfuric acid method, ${ }^{17)}$ the weight of the sample constituents in the capsule was confirmed. The transition temperature and the enthalpy were found from the DSC curve.

Fourier transform infrared spectroscopy (FT-IR). FT-IR spectra of starch chain solutions were obtained using a JEOL JIR-5000 FT-IR spectrophotometer with a TGS detector and a circle cell (Spectra-Tech, USA). In the case of each spectrum, a 100 scan interferogram was collected at $4 \mathrm{~cm}^{-1}$ resolution and deconvolution was accomplished using a JEOL IR-PRO 278 deconvolution program after subtracting background spectrum. Curve fitting was done with a JEOL IR-270 curve fitting program. The lyophilized samples were dissolved in distilled water or $2 \mathrm{~m}$ sodium hydroxide at a concentration of $1 \%$. Amylose dissolved in $0.01 \mathrm{M}$ borate solution ( $\mathrm{pH} 7.0$ ) was prepared from a $2 \mathrm{M}$ sodium hydroxide solution by displacement, by passing it through an AmpureTMSA column (Amersham Pharmacia Biotech, Uppsala, Sweden) equilibrated with $0.01 \mathrm{M}$ borate buffer ( $\mathrm{pH}$ 7.0). Amylose-iodine complex solution was prepared by adding $0.05 \mathrm{ml}$ of $0.2 \%$ iodine- $2 \%$ potassium chloride solution to $1 \mathrm{ml}$ of amylose in $0.01 \mathrm{M}$ borate buffer ( $\mathrm{pH} 7.0$ ). Starch chains were dissolved in distilled water by incubation at $80^{\circ} \mathrm{C}$ for 20 min and cooled to $20^{\circ} \mathrm{C}$.

Analytical methods. The total saccharides content and the reducing sugar content were measured by the Somogyi ${ }^{18)}$-Nelson ${ }^{19)}$ method and the phenol-sulfuric acid method, ${ }^{17)}$ respectively. The reducing residue content and the non-reducing residue content were measured by the modified Park-Johnson method ${ }^{20)}$ and the rapid Smith degradation method, ${ }^{22)}$ respectively.

\section{Results and Discussion}

\section{Structural features of starch chains}

Acid-treated starch (ATS) with a 1\% hydrolysis rate was fractionated by chromatography using a Toyopearl HW-65S column with distilled water as the mobile phase, and the P-1 component eluted at the void volume was recovered. The yield was about $54 \%$. The fraction containing chains that permeated into the column was also recovered as the P-2 fraction. Since SEC analysis using $0.01 \mathrm{M}$ borate buffer ( $\mathrm{pH} 7.0$ ) containing $0.1 \mathrm{M}$ potassium chloride as the mobile phase showed that $\mathrm{P}-1$ was composed of distributed starch chains with a main relative molecular weight $(M \mathrm{r})$ of $4.87 \times 10^{4}$ (data not shown), P-1, a large aggregate, was considered to be formed through spontaneous molecular association or rearrangement of starch chains with $\mathrm{Mr} 4.87 \times 10^{4}$, as reported in a previous paper. ${ }^{15}$ ) This phenomenon may be related to the spontaneous organization or packing of starch molecules in starch granules during starch synthesis. P-1 was thus fractionated into 4 fractions (Frs. 1-4) according to $M r$. SEC analysis showed that the Mr of Fr. 1, Fr. 2, Fr. 3, and Fr. 4 recovered was $15 \times 10^{4}, 8.91 \times 10^{4}, 3.98 \times 10^{4}$, and $1.54 \times 10^{4}$, respectively. The chains in Fr. 2 completely associated to form the large aggregate eluted at the void volume, but the chains in Fr. 1, Fr. 3, and Fr. 4 did not completely associate and these fractions contained a small amount of non-associating chains (data not shown). Fr. 2 was selected for further study because of the typical spontaneous molecular association observed. The yield in the case of Fr. 2 was about $15 \%$ of that in the case of $\mathrm{P}-1$. 
The average degree of polymerization ( $\overline{\mathrm{DP}})$ of the chains in P-1, P-2, and Fr. 2 was calculated from the assay of reducing residues. ${ }^{20)}$ The molecular weight estimated (about 2,000) on the basis of the $\overline{\mathrm{DP}}$ was somewhat smaller than that estimated by SEC analysis (Table 1), because the weight average molecular weight $(M \mathrm{w})$ is usually larger than the number average molecular weight $(M \mathrm{n})$, and SEC shows an intermediate value between $M \mathrm{w}$ and $M \mathrm{n}$, evaluated on the basis of the DP. The average unit chain length $(\overline{\mathrm{CL}})$ of the chains in debranched samples, as measured by the assay of non-reducing residues, ${ }^{22}$ was about 3,300-3,700. However, SEC analysis of these samples showed double peaks at the same elution time, indicating the presence of two kinds of the unit chain (data not shown). The small chain (a chain) had a $M r$ of 2,700 and the large chain (b chain) had a $M r$ of 7,900 in all cases. The unit chain composition was evaluated by curve fitting of the original SEC pattern assuming that the main peak (a chain) showed a normal distribution. Since P-1 and Fr. 2 showed the same molar ratio $(7: 1)$ of a chain to $b$ chain, the chains in Fr. 2 were considered to have the same unit structure as that in the case of $\mathrm{P}-1$. The molecular weight of this unit structure was calculated to be 26,700 , corresponding to about $1 / 3$ of the molecular weight in the case of Fr. 2. The average molecular weight of the unit chain calculated from a chain content and $b$ chain content agreed well with the results calculated on the basis of $\overline{\mathrm{CL}}$ as shown in Table 1. The average branch number $(\overline{\mathrm{DP}} / \overline{\mathrm{CL}})$ per molecule in the case of Fr. 2 was 24.0 , equal to three times that (8) of the unit structure. $\beta$-Amylolysis limit (Table 1) in the case of P-1 and Fr. 2 was about $40 \%$,

Table 1. Structural Features of P-1, P-2, and Fr. 2 Obtained from Slightly Acid-Treated Potato Starch

\begin{tabular}{lccc}
\hline & P-1 & P-2 & Fr. 2 \\
\hline$M^{\mathrm{a}}$ & 48,700 & 7,300 & 89,100 \\
$\overline{\mathrm{DP}}$ & 311 & 29.8 & 540 \\
$(\overline{\mathrm{DP}} \times 162+18)$ & $(50,400)$ & $(4,800)$ & $(87,500)$ \\
$M \mathrm{r}^{\mathrm{a}}$ of unit chain a & 2,700 & 2,700 & 2,700 \\
& 7,900 & 7,900 & 7,900 \\
$\mathrm{a}: \mathrm{b}$ (molar ratio) & $7: 1$ & $20: 1$ & $7: 1$ \\
$\left(M_{\mathrm{r}}\right.$ of unit chainsc) & $(3,350)$ & $(2,950)$ & $(3,350)$ \\
$\overline{\mathrm{CL}}$ & 20.5 & 20.8 & 22.5 \\
$(\overline{\mathrm{CL}} \times 162+18)$ & $(3,340)$ & $(3,390)$ & $(3,660)$ \\
$\mathrm{BN}$ & 15.2 & 1.4 & 24.0 \\
$M \mathrm{r}^{\mathrm{a}}$ of $\beta$-limit dextrin & 31,600 & 6,300 & 47,300 \\
$\beta$-Amylolysis limit $(\%)$ & 44.8 & 91.2 & 39.9 \\
$M \mathrm{r}^{\mathrm{a}}$ of unit chain & 6,000 & 6,000 & 6,000 \\
of $\beta$-limit dextrin & & & \\
\hline
\end{tabular}

a Relative molecular weight was estimated by SEC.

b Average degree of polymerization was measured by the assay of reducing residues. ${ }^{20)}$

Average molecular weight of unit chains was calculated from molar ratio of $a / b$ chain.

d Average chain length was measured by the assay of non-reducing residues. ${ }^{22)}$

e branch number per molecule. indicating a highly branched structure, but that of P-2 showed about $90 \%$, indicating a higher content of linear structure. The chains in P-1 and Fr. 2 were thus considered to be mainly derived from the amylopectin fraction of the original starch, whereas the chains in P-2 was mainly derived from the amylose fraction. The $M \mathrm{r}$ of the $\beta$-limit dextrins produced from P-1 and Fr. 2 was about $50-65 \%$ of that of the chains in P-1 and Fr. 2 without $\beta$-amylolysis, but $\mathrm{P}-2$ gave $86 \%$ (Table 1 ), indicating that $\mathrm{P}-2$ contained a small amount of relatively large branched chains. The $M \mathrm{r}$ of the debranched $\beta$-limit dextrins were also evaluated. The results showed that all $\beta$-limit dextrins were composed of a unit chain with $M \mathrm{r} 6,000(\overline{\mathrm{DP}}=37)$. From these results, the chains in P-1 and Fr. 2 were thus considered to be soluble branched chains derived from amylopectin of potato starch and those in Fr. 2 were considered to be composed of three b chains with $M r 7,900$ and 21 a chains with $M r 2,700$.

\section{Thermal transition evaluated by DSC}

DSC was done to investigate the thermal transition of starch chains heated to $120^{\circ} \mathrm{C}$ and then held at $0^{\circ} \mathrm{C}$ for $30 \mathrm{~min}$ in the DSC heating furnace. The endothermic transition in water occurred in the temperature region of about $37-76^{\circ} \mathrm{C}$ in the case of native starch, ATS and P-1, but P-2 did not show a clear endothermic peak (Fig. 1). In particular, ATS and P-1 showed a large endothermic peak as described previ-

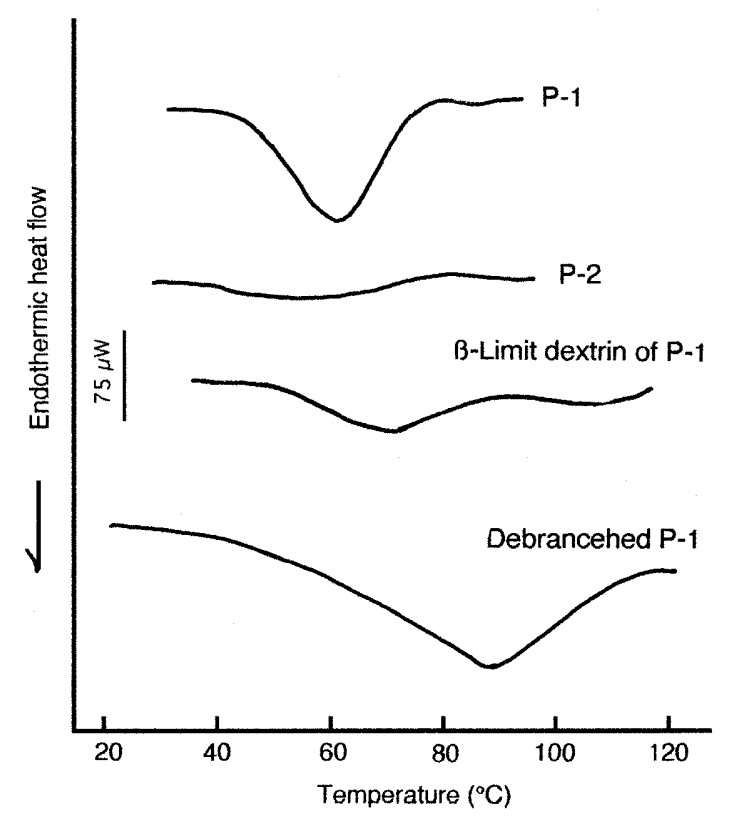

Fig. 1. DSC Curves for P-1, P-2, $\beta$-Limit Dextrin of $\mathrm{P}-1$, and Debranched P-1 Obtained from Slightly Acid-treated Potato Starch.

Sample preparation and analytical conditions of DSC, see Materials and Methods. After the first run to $120^{\circ} \mathrm{C}$, sample in the heating furnace was rapidly cooled to $0^{\circ} \mathrm{C}$ with liquid nitrogen, and then the second run was done. 
ously. ${ }^{15)}$ The SEC pattern of ATS heated to $120^{\circ} \mathrm{C}$ showed an unchanged molecular weight distribution as compared with that of the unheated ATS (data not shown). It is thus considered that the endothermic peak could serve to detect the thermal transition of the higher ordered structure of starch chains reconstituted during the cooling of ATS. Since DSC curves obtained in analysis of ATS and P-1 repeated four times showed a transition temperature and enthalpy similar to those observed in the second run, the thermal transition of ATS and P-1 observed was to be surely reversible. DSC curves obtained in the second run for Frs. 1-4 also showed a clear endothermic peak in a temperature region similar to that in the case of P-1 (Fig. 2). In particular, Fr. 2 and Table 2 showed a narrow transition range due to greater homogeneity in terms of molecular weight distribution than the others. In this study, it was reconfirmed that the starch chains in P-1 associated to form large aggregates in water or $0.01 \mathrm{M}$ borate buffer $(\mathrm{pH} 7.0)$, and dissociated in $0.01 \mathrm{M}$ borate buffer $(\mathrm{pH} 7.0$ ) containing $0.1 \mathrm{M}$ potassium chloride, as described previously. ${ }^{15)}$ In $0.01 \mathrm{M}$ borate buffer $(\mathrm{pH} 7.0)$ containing 0.1 or $0.5 \mathrm{M}$ potassium chloride, $\mathrm{P}-1$ showed an endothermic peak similar to that in water (data not shown), indicating that there was an intramolecular ordered structure in P-1 occurring in the thermal transition. Since no endothermic peak was observed in 1.0 or $3.0 \mathrm{M}$ guanidine hydrochloride, the ordered structure was probably mainly reconstituted by

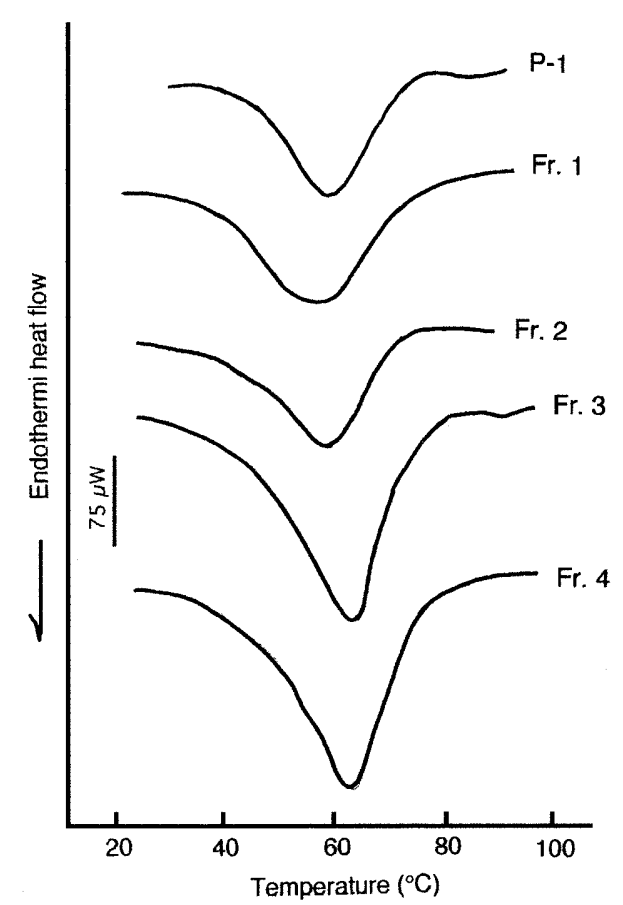

Fig. 2. DSC Curves for Frs. 1-4 Obtained from P-1.

Sample preparation and analytical conditions of DSC, see Materials and Methods. After the first run to $120^{\circ} \mathrm{C}$, sample in the heating furnace was rapidly cooled to $0^{\circ} \mathrm{C}$ with liquid nitrogen, and then the second run was done. hydrogen bonding. When the branched chains in P-1 were eliminated by $\beta$-amylolysis, the thermal transition of P-1 weakened greatly, as shown by a marked decrease in the enthalpy to about $1 / 4$ of that of P-1 (Fig. 1 and Table 2). The thermal transition of P-1 was thus considered to be mainly caused possibly by an ordered structure such as helix structure reconstituted with the branched chains as described below. Debranched P-1 showed a broad thermal transition which ceased above $100^{\circ} \mathrm{C}$ and very large enthalpy like that of amylose as compared with P-1 (Fig. 1 and Table 2). This also supports the view that the branched structure is important for the reversible thermal transition of starch chains.

\section{Thermal transition evaluated by FT-IR}

FT-IR spectra of $\mathrm{G}_{1}-\mathrm{G}_{8}$ were obtained in water at $25^{\circ} \mathrm{C}$. Deconvoluted FT-IR spectra of maltooligosaccharides showed eight absorption peaks in a wavenumber region of $920-1200 \mathrm{~cm}^{-1}$ (Fig. 3), which were assigned to $\mathrm{C}-\mathrm{C}$ and $\mathrm{C}-\mathrm{O}$ stretching. ${ }^{8}$ In particular, the peak (No. 7) at about $1024 \mathrm{~cm}^{-1}$ was strong and increased with the degree of polymerization, but glucose showed no peak at $1024 \mathrm{~cm}^{-1}$, but rather at $1018 \mathrm{~cm}^{-1}$, suggesting that peak No. 7 could be assigned to absorption due to the glucosidic linkage. FT-IR spectra of amylose (DP, about 980) were thus measured in $0.01 \mathrm{M}$ borate buffer $(\mathrm{pH} 7.0)$ and $2 \mathrm{M}$ sodium hydroxide to investigate the relation to higher ordered structure (Fig. 4). The relative intensity of the absorption peak of No. 5 to that of No. 7 (No. $5 /$ No. 7) decreased in $2 \mathrm{M}$ sodium hydroxide, but the relative intensity in the case of No. 8 increased in the opposite manner. Since amylose has a deformed helix at neutral $\mathrm{pH}$ at $25^{\circ} \mathrm{C},{ }^{23)}$ whereas

Table 2. Transition Temperatures and Enthalpies of P-1, P-2, and Fr. 2 Obtained from Slightly Acid-Treated Potato Starch Evaluated by DSC ${ }^{\text {a }}$

\begin{tabular}{|c|c|c|c|c|c|}
\hline & \multicolumn{3}{|c|}{$\begin{array}{c}\text { Transition } \\
\text { temperature }\left({ }^{\circ} \mathrm{C}\right)\end{array}$} & \multirow{2}{*}{$\begin{array}{c}\text { Transition } \\
\text { Range } \\
\left({ }^{\circ} \mathrm{C}\right)\end{array}$} & \multirow{2}{*}{$\begin{array}{l}\text { Enthalpy } \\
(\mathrm{mJ} / \mathrm{mg})\end{array}$} \\
\hline & $\mathrm{To}^{\mathrm{b}}$ & $T p^{c}$ & $\mathrm{Tc}^{\mathrm{d}}$ & & \\
\hline Native starch & 48.6 & 62.8 & 72.9 & 24.3 & 0.6 \\
\hline ATS & 37.1 & 58.9 & 76.4 & 39.3 & 3.7 \\
\hline P-1 & 39.1 & 59.9 & 70.5 & 31.4 & 2.2 \\
\hline P-2 & - & - & - & - & - \\
\hline Fr. 1 & 32.4 & 56.8 & 73.5 & 41.1 & 2.5 \\
\hline Fr. 2 & 40.3 & 60.9 & 71.8 & 31.5 & 1.5 \\
\hline Fr. 3 & 38.6 & 62.8 & 76.2 & 37.6 & 2.9 \\
\hline Fr. 4 & 39.8 & 62.9 & 76.3 & 36.5 & 3.2 \\
\hline $\begin{array}{l}\beta \text {-Limit dextrin } \\
\text { of } \mathrm{P}-1\end{array}$ & 42.6 & 66.8 & 82.4 & 39.8 & 0.4 \\
\hline $\begin{array}{l}\text { Debranched } \\
\text { P-1 }\end{array}$ & 45.7 & 89.6 & 104.4 & 58.7 & 16.0 \\
\hline
\end{tabular}

a After the first run to $120^{\circ} \mathrm{C}$, sample in the heating furnace was rapidly cooled to $0^{\circ} \mathrm{C}$ with liquid nitrogen, and then the second run was done.

b onset temperature.

c peak temperature.

d conclusion temperature. 


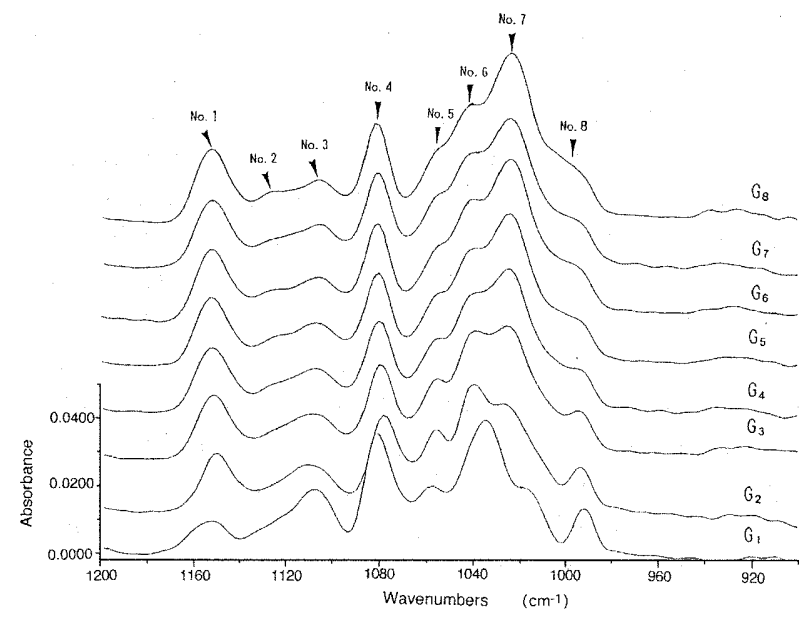

Fig. 3. Deconvoluted FT-IR Spectra of Maltooligosaccharides $\left(\mathrm{G}_{1}-\mathrm{G}_{8}\right)$.

Preparation of sample solutions and analytical conditions of FT-IR, see Materials and Methods.

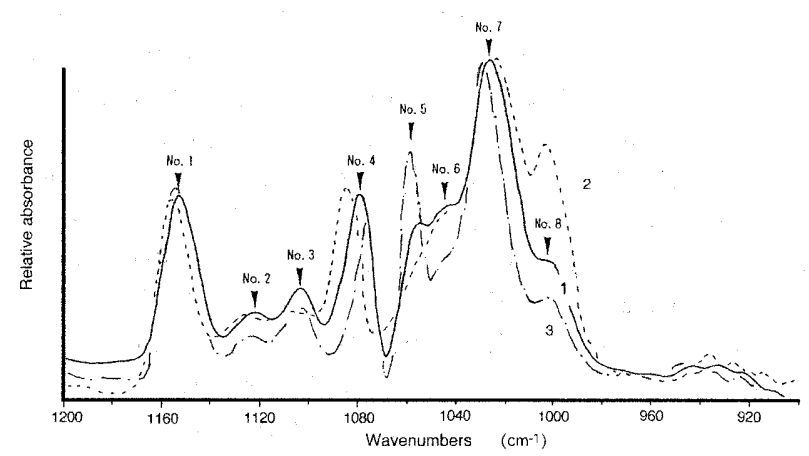

Fig. 4. Deconvoluted FT-IR Spectra of Amylose Solution. 1, $0.01 \mathrm{~m}$ borate buffer ( $\mathrm{pH} 7.0) ; 2,2 \mathrm{M}$ sodium hydroxide; 3 , amylose-iodine complex.

Preparation of sample solutions and analytical conditions of FT-IR, see Materials and Methods.

breakdown of the helical structure of amylose takes place in alkaline solution above $\mathrm{pH} 12,{ }^{24)}$ the peaks No. 5 and No. 8 may correspond to the helical structure and disordered structure of amylose, respectively. This assumption was supported by the observation that an amylose-iodine complex with a helix consisting of 6 glucose residues per turn with a pitch of $8 \AA^{25)}$ showed a marked increase in No. 5 peak intensity and a decrease in No. 8 peak intensity (Fig. 4).

P-1 dissolved at $80^{\circ} \mathrm{C}$ was cooled down to $4^{\circ} \mathrm{C}$ and held for $30 \mathrm{~min}$ to measure the FT-IR spectra (Fig. 5), and the results were very similar to those obtained in the case of maltooligosaccharides $\left(\mathrm{G}_{4}-\mathrm{G}_{8}\right)$. The deconvoluted FT-IR spectra of P-1 heated to a temperature in the range of $20^{\circ} \mathrm{C}$ to $80^{\circ} \mathrm{C}$, at every $10^{\circ} \mathrm{C}$ interval, for $30 \mathrm{~min}$ showed a relatively large change in peak intensity of No. 5 and No. 8 . In order to analyze the changes in higher ordered structure of $\mathrm{P}-1$ on the basis of the change in deconvoluted spectra of No. 5 and No. 8 , the No. 5-No. 8 peaks were

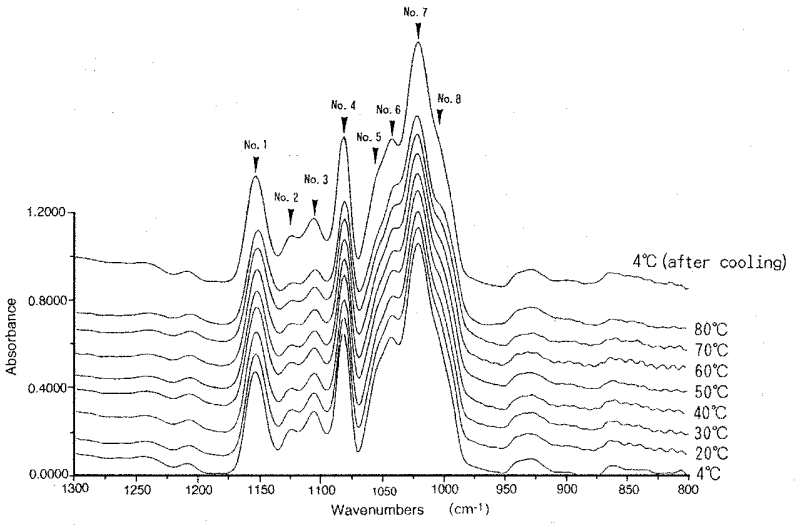

Fig. 5. Deconvoluted FT-IR Spectra of P-1 during Heating and Cooling.

P-1 solution in a circle cell was heated or cooled at indicated temperatures for $30 \mathrm{~min}$ to measure FT-IR spectra. Preparation of sample solutions and analytical conditions of FT-IR, see Materials and Methods.

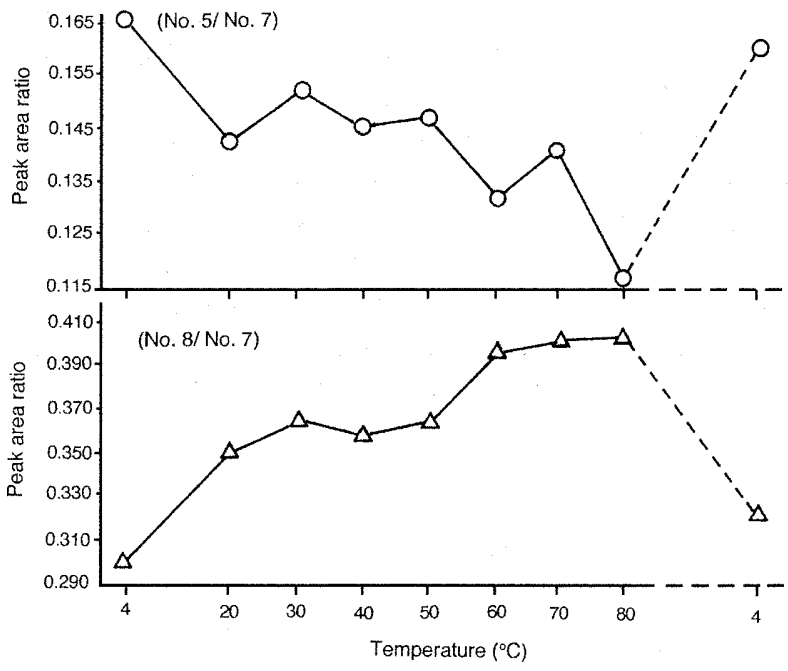

Fig. 6. Peak Area Ratios (No. 5/No. 7 and No. 8/No. 7) of P-1 during Heating and Cooling Evaluated by FT-IR.

No. 5-No. 8 peaks were curve-fitted to obtain the individual peak area of No. 5 , No. 6, No. 7, and No. 8, and each peak area ratio to No. 7 was calculated.

curve-fitted to obtain good agreement between the observed and the combined spectra using the line drawn through the data at $980 \mathrm{~cm}^{-1}$ and $1068 \mathrm{~cm}^{-1}$ as a baseline, and the individual peak area of No. 5 , No. 6 , No. 7 , and No. 8 was thereby obtained. The ratio of the peak area of No. 5 and No. 8 to that of No. 7 was plotted against the temperature (Fig. 6). The relative peak area of No. 5, which was considered to be closely connected with ordered structure, which is considered to be helix structure, showed an obvious decrease at $50-60^{\circ} \mathrm{C}$ and at $70-80^{\circ} \mathrm{C}$ during re-heating. The relative peak area of No. 8 , which was considered to be closely connected with the disordered structure, showed a considerable increase at $50-60^{\circ} \mathrm{C}$. The temperature range in which the change 
in FT-IR spectra occurred agrees well with that of the thermal transition as evaluated by DSC. It is thus considered that FT-IR could be used to investigate the thermal transition of ordered structure, like the helix-coil transition, of soluble starch chains. Upon re-cooling to $4^{\circ} \mathrm{C}$, both relative ratios returned to values close to the starting values. It is thus considered that the thermal transition detected by FT-IR is also reversible. However, FT-IR spectra of $\beta$-limit dextrins showed no substantial change during heating and cooling (data not shown), suggesting that the branched chains mainly take part in the reconstitution of ordered structure in the case of P-1. From these results, it seems evident that further analysis of the soluble branched chains with uniform molecular weight prepared in this study may contribute to elucidate the mechanism of the organization of starch molecules and the complicated physical properties of starch, through examination of the spontaneous molecular association and reversible thermal transition.

\section{Acknowledgments}

We are very grateful to Dr. Sakano of Tokyo University of Agriculture and Technology, Dr. K. Yamamoto of Hokuren Research Institute and Dr. T. Nakakuki of Nihon Shokuhin Kako Co., Ltd. for the kind gift of pullulanase, the large granule preparation of potato starch, and maltooligosaccharides, respectively.

\section{References}

1) Hizukuri, S., Takeda, Y., Abe, J., Hanashiro, I., Matsunobu, G., and Kiyota, H., Analytical developments: Molecular and microstructural characterization. In "Starch: Structure and Functionality", eds. Frazier, P. J., Richmond, P., and Donald, A. M., The Royal Society of Chemistry, Cambridge, pp. 121-128 (1997).

2) Jane, J., Chen, Y. Y., Lee, L. F., McPherson, A. E., Wong, K. S., Radosavljevic, M., and Kasemsuwan, T., Effect of amylopectin branch chain length and amylose content on the gelatinization and pasting properties of starch. Cereal Chem., 76, 629-637 (1999).

3) Zobel, H. F., X-ray analysis of starch granules. In "Methods in carbohydrate chemistry", ed. Whistler, R. L., Academic Press, Inc., New York, pp. 109-113 (1964).

4) Bail, P. L., Buleon, A., Colonna, P., and Bizot, H., Structural and polymorphic transitions of amylose induced by water and temperature changes. In "Starch: Structure and Functionality", eds. Frazier, P. J., Richmond, P., and Donald, A. M., The Royal Society of Chemistry, Cambridge, pp. 51-58 (1997).

5) Stevens, D. L. and Elton, G. A. L., Thermal properties of the starch/water system. Part 1. Measurement of heat gelatinization by differential scanning calori- metry. Stärke, 23, 8-11 (1971).

6) Wada, K., Takahashi, K., Shirai, K., and Kawamura, A., Differential thermal analysis (DTA) applied to examining gelatinization of starches in foods. J. Food Sci., 44, 1366-1372 (1979).

7) Yamaguchi, M., Kainuma, K., and French, D., Electron microscopic observations of waxy-maize starch. J. Ultrastruct. Res., 69, 249-261 (1979).

8) Goodfellow B. J., and Wilson, R. H., A Fourier transform IR study of the gelation of amylose and amylopectin. Biopolymers, 30, 1183-1189 (1990).

9) Wilson, R. H., Goodfellow, B. J., and Belton, P. S., Comparison of Fourier transform mid infrared spectroscopy and near infrared reflectance spectroscopy with differential scanning calorimetry for the study of the staling of bread. J. Agric. Food Chem., 54, 471-483(1991).

10) Iizuka, K. and Aishima, T., Starch gelation process observed by FT-IR/ATR spectrometry with multivariate data analysis. J. Food Sci., 64, 653-658 (1999).

11) Bulkin, B. J., Kwak, Y., and Dea, I. C. M., Retrogradation kinetics of waxy-corn and potato starches: A rapid, Raman-spectroscopic study. Carbohydr. Res., 160, 95-112 (1987).

12) Gidley, M. J. and Bulpin, P. V., Aggregation of amylose in aqueous solutions; the effect of chain length on phase behavior and aggregation. Macromolecules, 22, 341-346 (1989).

13) Nilsson, G. S., Bergquist, K., Nilsson, U., and Gorton, L., Determination of the degree of branching in normal and amylopectin type potato starch with ${ }^{1} \mathrm{H}$ NMR spectroscopy. Stärke, 48, 352-357 (1996).

14) Kainuma, K. and French, D., Nägeli amylodextrin and its relationship to starch granule structure. 1. Preparation and properties of amylodextrins from various starch types. Biopolymers, 10, 1673-1680 (1971).

15) Takahashi, K., Hattori, M., and Wada, K., Reversible molecular rearrangement of slightly acid-treated starches. J. Food Sci., 59, 637-640 (1994).

16) Vertblad, P., Biospecific affinity chromatography of sweet-potato $\beta$-amylase. FEBS Letters, 47, 86 (1974).

17) Dubois, M., Gilles, K. A., Hamilton, J. K., Reber, P.A., and Smith, F., Colorimetric method for determination of sugars and related substances., Anal. Chem., 28, 350-356 (1956).

18) Somogyi, M., Notes on sugar determination. J. Biol. Chem., 195, 19-23 (1952).

19) Nelson, N. J., A photometric adaptation of the Somogyi method for the determination of glucose. $J$. Biol. Chem., 153, 375-380 (1944).

20) Hizukuri, S., Takeda, Y., Yasuda, M., and Suzuki, A. Multibranched nature of amylose and the action of debranching enzymes. Carbohydr. Res., 94, 205(1981).

21) Takahashi, K., Shirai, K., and Wada, K., Melting behavior of gels prepared from isolated subunits of collagen. J. Food Sci., 53, 1920-1921 (1988).

22) Hizukuri, S. and Osaki, S., A rapid Smith-degradation for determination of non-reducing terminal residues of $(1,4)$-alpha-D-glucans. Carbohydr. Res., 63, 261-264 (1978). 
23) Kitamura, S. and Kuge, T., Study of polysaccharides by fluorescence method. 3. Chain length of the microBrownian motion of amylose in aqueous solution. Biopolymers, 23, 1043-1056 (1984).

24) Rao, V. S. R. and Foster, J. F., Studies of the conformation of amylose in solution. Biopolymers, $\mathbf{1}$,
527-544 (1963).

25) Rundle, R. E. and French, D., The configuration of starch in the starch-iodine complex. 3. X-ray diffraction study of the starch-iodine complex. J. Amer. Chem. Soc., 65, 1701 (1943). 